\title{
The Challenges Facing Ceramic Industries in Ghana: Its Impact on Ceramic Education in Ghana
}

\author{
Kofi Asante-Kyei \\ Department of Ceramic Technology, Takoradi Technical University, Takoradi, Ghana \\ Email address: \\ kofi.asante-kyei@ttu.edu.gh

\section{To cite this article:} \\ Kofi Asante-Kyei. The Challenges Facing Ceramic Industries in Ghana: Its Impact on Ceramic Education in Ghana. Higher Education \\ Research. Vol. 4, No. 2, 2019, pp. 30-35. doi: 10.11648/j.her.20190402.12
}

Received: April 1, 2019; Accepted: May 9, 2019; Published: June 5, 2019

\begin{abstract}
Of late, there have been challenges facing the Ceramic Industry in Ghana that are affecting the study of ceramics in Ghanaian ceramic education, especially tertiary education. Therefore, this study seeks to examine and discuss the impact of the challenges of Ghana's ceramic industry on ceramic education in Ghana. The population of the study comprised students, lecturers and heads of department of selected ceramic education tertiary institutions in Ghana as well as stakeholders in Ghana's ceramic factories. The methodology employed was the qualitative approach and the descriptive survey. The research instruments used to gather data were interview and observation. It was found among others, that the establishment of metal and plastic factories in Ghana and the importation of metallic and plastic plates, blenders, metallic cooking pots and plastic buckets into the country have contributed to the reduction of intake of ceramic students in ceramic education institutions. The study recommends among others that, the government of Ghana should protect indigenous industries by means of tax incentives, invest in local ceramic industries by giving subsidies for the acquisition of new machinery, equipment, human resources and manpower development. Additionally, measures should be put in place for the provision of logistics and equipment to facilitate teaching and learning to make the ceramic graduate marketable and employable.
\end{abstract}

Keywords: Ceramic Industry, Ceramic Education, Challenges and Obsolete

\section{Introduction}

The Ceramic Industry in Ghana was once a very vibrant industry, which employed sizable workers [1]. Saltpond Ceramics; Tarkwa Glass Factory; Ekem Ceramics, Winneba; and Ceramica Tamakloe, Dodowa; Happy Ceramics, Accra; were just a few to mention. Most of these companies in the industry produced high quality ceramic wares, which had high patronage on the local, West African and international markets. Finished ceramic wares such as sanitary wares, cups, plates, bowls, flower pots, glass, bricks, tiles, water coolers and many others produced by these companies were in high demand on the Ghanaian market because they were predominantly used in the food and beverage industries, households and building industries. The industry was not only a source of employment to sizable Ghanaians but also contributed to about $1 \%-2 \%$ of the country's total Gross Domestic Products (GDP), [2]. In trying to consolidate the gains the nation had made, in respect of this industry at the time, the government of Ghana established academic institutions to train students in ceramics, so as to take up different responsibilities in the ceramic industry.

Of late, the industry has gone through difficult moments resulting in closing down of production of most of the companies in the industry and a lot of workers have been redundant as a result of these shut downs [3]. The study observed that, that has affected the employment of ceramic graduates in such companies whose establishments were tailored towards providing manpower for the ceramic industry.

The ceramic industry in Ghana over the past years has been gradually reducing in terms of growths and development. Apart from the consequent negative economic outcomes being experienced by the country, the education institutions that were established by the government of Ghana to provide the industry with the necessary skilled manpower also appears to be retrogressing concurrently with it. 
Table 1. Enrolment of Ceramic Students in Selected Tertiary Institutions.

\begin{tabular}{lll}
\hline Name of Institution & Academic Year & Enrolment \\
\hline & 2014 & 55 \\
Takoradi Technical & 2015 & 48 \\
University & 2016 & 40 \\
& 2017 & 38 \\
& 2014 & 133 \\
University of Education, & 2015 & 60 \\
Winneba & 2016 & 78 \\
& 2017 & 33 \\
\hline
\end{tabular}

Source: Academic records of students in various Departments

From table 1, in the year 2014, the number of students admitted by Takoradi Technical University (TTU) formerly Takoradi Polytechnic was 55, and was reduced to 48 in the year 2015. Enrollment in the year 2016 was subsequently reduced to 40 and in the year 2017, it was 38 (Department of Ceramic Technology - Takoradi Technical University, 2017). At the University of Education, Winneba the intake was 133 in the year 2014, 60 in the year 2015, 78 in the year 2016, and drastically reduced to 33 in the year 2017 (Ceramic section - UEW, 2017). At Opportunity Industrialization Centre (O.I.C), Sekondi (ceramic section) and KNUST, Kumasi (Ceramics section) could paint the same disturbing picture of the situation.

There is therefore the need to conduct an in-depth investigation into the ceramic industry and how it has affected Ceramic Education in Ghana, to enable appropriate solutions to be made for the problems identified.

\subsection{Purpose of the Study}

The study seeks to examine and discuss the impact of the challenges of Ghana's ceramic industry on ceramic graduates.

\subsection{Overview of the Ghanaian Ceramic Industry}

Over the years, ceramic education in Ghana has been generally tailored towards preparing the required specialized educated and skilled technicians in the field of ceramics (mould and casting, hand building, throwing, brick and tiles, glazing, jiggering, majolica, materials preparation, etc,) to fill various positions in the industry as well as educational sector. Quartey [4] opines that industrial development has been recognized as one of the surest means of ensuring higher and sustained growth in the world rates. Hence, Ghana pursued import substitution industrialization (ISI) in the 1960s and 1970s. The rationale was to move her economy from their agrarian (agriculturally driven) state to a modern industrialized economy. Policies to promote import substitution industrialization were accordingly pursued and this led to the establishment of light industries to produce goods locally and operate behind tariff barriers. Ghana's industrial approach was meant to reduce economic dependence; hence, manufacturing industries were established to produce items that were previously imported.

As a result, industries manufacturing ceramic wares, and other important commodities were established and contributed significantly to the livelihood of Ghanaians. Key among some of the ceramic manufacturing companies were Saltpond Ceramics; Tarkwa Glass Factory; Ekem Ceramics, Winneba; and Ceramica Tamakloe, Dodowa; Happy Ceramics, Accra; Council for Scientific and Industrial Research (CSIR, ceramic section), Accra; Building Research and Road Institute (BRRI, ceramic department), Kumasi; National Centre for Culture (ceramic sections), Kumasi and Accra; and Geological Survey Department (ceramic section) Accra; Vicalex Bricks and Tiles Production, Kumasi. Beside these medium to large scale ceramic factories, there were hundreds of small scale ceramic and pottery setups scattered across the length and breadth of the country whose contributions to the state were phenomenal. However, due to inconsistent government policies over the years, the production of ceramic wares has considerably declined in Ghana. The Trade Liberalization Policy, which formed part of Ghana Government's Structural Adjustment Programme pursued in the 1980s and 1990s paved way for increased in the establishment of metal and plastic factories in Ghana in the wake of urbanization and the importation of refrigerators, metallic and plastic plates, cups, bowls, flower pots, tiles, blenders, metallic cooking pots and plastic buckets into the country. The items either serve or have similar purposes for the ceramic products.

Happy [5] attests to the fact that most of the ceramic industries have shut down due to cheap imports from China. He argues that not only is Chinese plastic product less durable as compared to made-in-Ghana ceramic products, but also sells far below the price of Ghanaian ceramic products.

Industry observers are worried that if the flood gates are opened for the foreign ceramic products to saturate the Ghanaian market, then the industry will totally collapse. They posit that the current situation has made it difficult for local producers of ceramics and pottery to sustain production levels and to operate profitable. They believe that the dwindling fortunes can be addressed if the Government strengthens agencies such as the Customs Excise and Preventive Service (CEPS) to intensify border patrols. They further suggest that the port operations should be tightened to ensure that cheap imports do not sneak in. But how well and soon will the authorities respond to the calls that remain an issue of concern to ceramic industry players whose hope of continued survival in the business depend on it? However, Ekem [6] argues that the use of obsolete technology by local ceramic and pottery manufacturers is the bane behind their problems and not unfair competition. According to him, the industry cannot do well when it is still operating with machines that are over 40 years old. It is therefore very clear that the ceramic industry is in very difficult times and its current situation needs immediate attention to curb it from total collapse.

\section{Method}

This section represents the methodology that was adopted 
in conducting the study. The design is based on qualitative research method with emphasis on the description of problems that are endangering the ceramic industry and how they are affecting Ceramic Education in Ghana. The section also highlights information on the research instruments employed for gathering the data needed to answer the research questions, the population studied, sampling design and data processing methods.

\section{Research Design}

In this study, the purposive and convenience sampling have been used concurrently. The purposive sampling involves selecting individuals known to meet certain clear criteria. In other words, it targets a particular group of people who have direct information in relation to a study [7]. The reason for using the purposive sampling is that the selection of the population meets the objectives of the research. Hence, the population of 78 was selected. The items (questions) in the interview guide were not lengthy and too demanding, therefore the researcher was able to effectively manage. Wadsworth [7] explains that convenience sampling is a nonprobability sampling technique where subjects are selected because of their convenient accessibility and proximity to the researcher. The convenience sampling was used in areas where the respondents were not ready to speak due to confidentiality of data. The study had to solely rely on those who were ready and willing to speak, but under extreme anonymity, for fear of victimization.

\section{Discussions}

This part interprets and analyses data collected for the study and provides the necessary basis for findings and conclusions of the study. Most of the findings that are presented in this section are highly confidential, so industries and personnel that participated in the study pleaded strict anonymity. However, the data presented can make or unmake the ceramic industry.

\subsection{Influx of Ceramic Products from Foreign Countries}

The findings of the study showed that, competition in the ceramic industry in the distance past was just among the local industries but the equation has changed. The local companies now have to compete with influx of ceramic products or similar products from China and other countries. These products seem to offer value for money and are affordable. To compete with these foreign products will mean the local producers reducing their prices. This will also mean they will be under pricing their products and this will have dire consequences on their profit margins. Most of the interviewees engaged clearly opined that the threats to Ghana's ceramic industry stemmed from problems at the ECOWAS regional borders. Some ECOWAS countries, notably Nigeria, have banned the importation of certain ceramic goods; and as a result, the entry of ceramic and similar products into Ghanaian market through unofficial channels had also become a problem, depressing the market for locally produced ceramic wares

\subsection{Evasion of Duty on Imported Ceramic or Similar Products}

Another important finding from the study was the fact that importers of ceramic or plastic products with similar functions in most cases did not pay realistic duties in Ghana basically because they:

(i) Under-declared their imports (declaring lower quantities than was actually brought into the country. In some cases, out of eight (8) containers imported duty was paid on only two (2) containers and the same documents were recycled to clear the other six (6) containers without payment of duties).

(ii) Under invoiced their imports (thus, declaring lower values rather than the actual value in order to attract lower duties).

(iii) Were not honest in their imports descriptions (thus, fraudulently misrepresenting the actual type of ceramic products imported. For example, cups and bowls instead of glazed tiles which attract higher duty.

This unfair advantage made these imports have cheaper marks up than the locally produced ceramic wares that are highly taxed.

\subsection{Exorbitant Utility Cost Affecting Ceramic Production}

In Ghana, one of the biggest problems faced by the manufacturing sector and for that matter, the ceramic industry is the exorbitant energy cost and that of water. In other countries such as China, Japan, United States of America, United Kingdom, and Korea, water and electricity use for the manufacturing sector is highly subsidized by the government, whereas in Ghana, full costs of electricity and water are borne by local manufacturers. Additionally, cost of ceramic raw materials is comparatively lower in foreign countries as against importation of certain raw materials such as glazes into Ghana. This is due to import duty and the dollar-cedi rates. It could be inferred from the above that, because the biggest chunk of the cost of production of foreign ceramic firms is highly subsidized by their various governments, their products are far cheaper as compared to those produced by Ceramic Manufacturers in Ghana, since the cost of production in Ghana is extremely high.

\subsection{Obsolete Machine in the Ceramic Industry}

It was found out that most of the ceramic and pottery industries in Ghana made use of obsolete and outdated machines; and that is why they are finding it very difficult to compete with the foreign ceramic products. Assuming that is true, what it means is that their cost of production will increase due to loss of man-hours as a result of machine breakdowns and stoppages in production lines. This cost is likely going to be passed onto the consumer. Secondly, old machines are likely to be less efficient. This will lead to the companies not meeting their production targets for any given time. The implication is that there will be delays in meeting orders and this could result in customer dissatisfaction. 


\subsection{Poor Attitude of some Ceramic Factory Workers}

The attitude of some unscrupulous workers in the Ghanaian ceramic industry, have largely contributed to the woes of the sector. Issues such as theft, lackadaisical attitude towards work, bad customer care practices, absenteeism, under invoicing and over invoicing have combined to hasten the decline of many of the ceramic and other industries in Ghana [8]. It came out that there have been incidences of theft of finished goods, materials, and machine parts in the ceramic factories by workers. Again, unavailability of raw materials and cost; and loose government policies were also serious factors that had led to the collapse of ceramic industries [9].

\subsection{The Effects of Ceramic Education in Ghana by the Deplorable State of the Ceramic Industry}

Responses from key players of the ceramic industry indicated on obvious admission that the current state of the industry has had an adverse effect on Ceramic Education in Ghana. Their argument was that, because the industry was not doing well; especially with the consistent laying-off of workers, many students were no more motivated enough to pursue ceramics as a programme. Another interesting allusion they made (i.e, Ekem Ceramics, ceramica Tamakloe and Vicalex) made was to the fact that, the number of ceramic students who used to pursue training attachments at their individual factories had dwindled at a very drastic rate over the past few years.

It could be inferred that, the responses from alumni, students, and teachers of ceramics only go to confirm the fact that the interest of students in the pursuit of ceramics as a programme had reduced. Almost all the 5 Lecturers of ceramics interviewed, admitted that the enrolment of students for ceramic students had been dwindling and called for pragmatic measures between industry and academia to salvage the situation. Out of the 78 ceramic students interviewed, only 7 of them, representing $9.0 \%$ of their totality admitted they found the study of ceramics interesting, and were actually going to be ceramists and ceramic artists after school. Again, out of the 95 ceramic alumni interviewed, only 5, representing $5.3 \%$ were working within the ceramic industry. The other $94.7 \%$ were all working within other sectors of the economy, rather than ceramics [10]. Over the past five years, admissions into Takoradi Polytechnic; University of Education, Winneba; and Opportunity Industrialization Centre (O.I.C) - ceramic section, Sekondi had drastically reduced. That of KNUST has remained inconsistent and kept fluctuating [10]. It could therefore be conveniently deduced from the above information that the majority of students currently pursuing ceramics will not end up in the ceramic industry but other sectors of the economy.

\subsection{The Future of the Ceramic Industry Side by Side Ceramic Education in Ghana}

It was found out that Ghana's ceramic industry risks total collapse if nothing is done immediately to alleviate it from its current state. Its effect on Ceramic Education in Ghana has been incredibly disturbing, and requires an urgent solution. It is clear that, the problem of the ceramic industry still persists, and as suggested by some of the interviewees, perhaps, a lot of political will, will help in the quest to get the industry on its feet. Trade policy is an integral part of a country's development strategy. Therefore, Ghana should ensure that trade arrangements are consistent with her development strategies and that they assist her in achieving her broad development goals. A related concern is the debate over trade liberalization and its effect on Ghana's economy. The Ministry of Trade and Industry needs a concerted effort at collaborating with the Ministry of Education and academia (Ceramic Education Institutions) to also rope-in strategies that would be beneficial to the growth and sustenance of ceramic education in Ghana. As has been admitted by some of the respondents, the story of Nigeria having banned some kinds of ceramic wares into her corridors, may have seemed harsh, but has by and large protected and facilitated the development of the local ceramic industry in that country by boosting the patronage of the local ceramic industry.

It has been established that many African countries have not been able to take full advantage of the available preferential external market access opportunities due to binding supply constraints [8]. In the case of Ghana, according to Lall [11], "the low level of capabilities in Ghana have meant that rapid liberalization, unaccompanied by supply-side measures to develop skills, capabilities and technical support, led to significant and costly deindustrialization. He continues, "the rapid pace of industrialization is killing-off not just inherently economic activities but also some measures that could be the basis of new manufactured exports" (p. 226). The same or similar set of constraints appear to be frustrating the derivation of longterm benefits from the reduction of domestic trade barriers implemented in many African countries since the early 1980s. Thus, these countries are reluctant to embark on further trade liberalization until this issue is appropriately analyzed and policy guidance offered.

From the analysis, it has also been established that the Ghana Education Service (GES) through the Curriculum and Research Development Department (CRDD) [12], urgently bring on board the ceramic industry and academia (the Senior High Schools and tertiary level) in the design or preparation of a reviewed ceramic and pottery syllabus for the SHS as well as the tertiary level, so as to keep them in tune with the different needs of the industry. It can be inferred from the various thoughts discussed that, the future of ceramic education in Ghana greatly depends on the unhindered growth of the ceramic industry. The better it does, the more students and prospective students of ceramics would be excited to pursue ceramics as a programme. Academia would invariably become more useful in the area of research, development and training to the ceramic industry in Ghana. 


\section{Conclusions}

From the main findings of the study, the following conclusions have therefore been drawn:

It can be expediently concluded that the ceramics industry in Ghana is in a deplorable state and therefore, calls for pragmatic policies that will lead to a rigorous restructuring of the industry. A gamut of the following challenges including poor attitude of factory workers, smuggling of ceramic wares into Ghana, under-declared imports, and wrongly described ceramic or similar products imports have all contributed adversely to the decline of the intake of ceramic students admitted into ceramic education institutions. Massive importation $(80 \%)$ as against very little export $(20 \%)$ and high cost of ceramic and pottery production have combined to hasten the current declining stage of the industry.

Additionally, it can also be concluded that the current state of the Ceramic Industry has taken toll on the ceramics education institutions that were established to train the requisite skilled manpower needed by the industry. Consequently, students are no longer motivated to pursue Ceramics Programmes. Accordingly, overwhelming majority of graduates of ceramics at the tertiary level are currently working within other sectors of the economy rather than ceramics. Current students pursuing ceramics at the various ceramic education institutions across the country would end up in other sectors of the economy rather than the ceramic industry because the ceramic industry does not look good.

It therefore behoves on the government of Ghana and every stakeholder of the ceramic industry such as manufacturers, importers and wholesalers of ceramic and pottery products, as well as academia to make a concerted effort to ensure that right things are done to revamp the ceramic industry.

Based on the findings and conclusions of the study, it is recommended that:

1. In order for the local ceramic industry to become more competitive and vibrant, the Government of Ghana (GOG) should give investment support to the ceramic industry. More investments are required in the sector by local, foreign investors and the government. Access to financial support, by the ceramic industry is one high area which needs major government support. Transport and information infrastructure needs immediate upgrading. Electricity, water, fuel and transportation cost occupied a higher percentage in the total cost of production (approximately 25\% of total cost) in the ceramic manufacturing processes. With the provision of good transport system, information infrastructure and energy quotas by the Government of Ghana, the ceramic sector will be in a very good position to compete very well on both local and international markets.

2. The government of Ghana should as a necessity within the framework of the constitution of Ghana through Parliament put together the necessary laws to treat smuggling of ceramic products into Ghana, the under- declaration of imports, and wrong description of ceramic imports, like illicit drugs related matters or treasonable offences that will attract high punishments from the state when a person or groups of persons become culpable. This will serve as an effective deterrent for future defaulters.

3. In dealing with attitudes and skills of workers, the managers of local ceramic companies should address the need of motivating workers by upgrading their skills through training programmes designed towards increasing productivity and to modernize the industry through improved technology and methods that allow for innovation and efficiency.

4. In order to clean the local market of inferior ceramic or similar products, the Government of Ghana through the Ministry of Trade and Industry (MOTI) should market Ghana as an ethical source of goods, requiring commitment from businesses and governments to eliminate sweatshops, in order to capture a share of the "Trade Fair" market especially in relation to ceramics manufacture.

5. In dealing with the unpleasant state of ceramics education, the Government of Ghana should commit herself at ensuring that Ceramics Education Institutions in Ghana (both at the Senior High School and Tertiary Levels) are given the requisite attention they need, in order to be able to stand the test of time. The provision of standard studios, laboratories for practical works which includes electrical potter's wheels, pug mills, plungers, extruders, clay mixers, glaze preparation machines, electric kilns, and many others. Senior High Schools that hitherto offered Ceramics as a subject; but have stopped because of the lack of the necessary inputs and logistics, will obviously start again, because government must have provided a solution to that peculiar challenge.

6. Government of Ghana in collaboration with the ceramic industry and the ceramic education institutions should find possible means of coming out with an aggressive strategy, tailored towards starting the manufacture of contemporary ceramic products such as sanitary wares, porcelain, roofing tiles, and others in Ghana. If it is realized, the hopes and aspirations of the ceramic industry would be rekindled, because it would generate massive employment, and would, as a result, motivate more students offer ceramics. The ceramic education institutions then would grow from strength to strength and their teachers would keep their jobs.

It is expected that, if the Government of Ghana, strategizes and considers the above mentioned recommendations, ceramic education in Ghana will be back on its feet again.

\section{Acknowledgements}

The author wishes to thank the following ceramists and ceramic artists for the audience granted me during the course of the research; R. C. Ekem, G. Happy, C. Tamakloe, and J. 
Nsiah. A special thanks also goes to Lecturers and students of Department of Ceramic Technology, Takoradi Technical University.

\section{References}

[1] Tamakloe, C. (2014, May 13). "Challenges facing Ghana's Ceramic Industry”. (Kofi Asante-Kyei, Interviewer).

[2] Ministry of Trade and Industry-Ghana (2004). Report on the Survey of Medium and Large Manufacturing. Accra: Government of Ghana.

[3] Nsiah, J. (2014, September 15). "Challenges facing Ghana's Ceramic Industry”. (Kofi Asante-Kyei, Interviewer).

[4] Quartey, P. (2006). "Textiles in Ghana. In the Textiles and Clothing Industry in Ghana" (p.2). Accra, Ghana: FiedrichEbert-Stiftung. BIBIOGRAPHY /11033.

[5] Happy, G. (2013, September, 6). “China Quietly Usurps African Ceramic Market.” (Kofi Asante-Kyei, Interviewer).
[6] Ekem, R. C. (2014, August 18). "Challenges facing Ghana's Ceramic Industry”. (Kofi Asante-Kyei, Interviewer).

[7] Wadsworth, C. (2005). "Sampling Methods: Purposive Sampling in Research Methods." New York: Cengage Learning. (p.29).

[8] Lokko, E. (2014, July, 20). "The Implications of the challenges facing Ghana's Ceramic Industry". (Kofi AsanteKyei, Interviewer).

[9] (Field survey, 2015). "A Visit by the Researcher to certain Ceramic Industries in Ghana". (Kofi Asante-Kyei, Researcher).

[10] (Field survey, August 2017). "Interviews Conducted On Selected Institutions" (Kofi Asante-Kyei, Researcher).

[11] Lall, S. (1995). Structural Adjustment and African Industry. World Development: Vol.23, No 12, p.226.

[12] Ministry of Education, Science and Sports, Ghana. (2008). Ceramic Education in Ghana. In Teaching Syllabus for Ceramics: SHS 2-4 (p. x). Accra: Government of Ghana. 